\title{
Éramos bossa nova hoje somos sin papeles: transnacionalismo, pertencimento e identidade nas representações dos migrantes latino-americanos e brasileiros na Espanha'
}

\author{
Rafael Tassi Teixeira
}

\begin{abstract}
resumo $\mathrm{O}$ artigo pretende traçar uma reflexão sobre a questão contemporânea do estabelecimento das séries de diferenças e demarcaçôes no âmbito das representaçôes transnacionais, sendo a preocupação maior discutir a etnicidade fluída desde um eixo central - memória cultural e identidade transnacional - observando as representaçóes dos coletivos latino-americanos e brasileiros na Espanha em seus novos fluxos migratórios. Os discursos étnicos como discursos descaracterizados e a imagem "tropicalista" dos brasileiros na Espanha. Serão analisadas a questão da recém-descoberta identidade latino-americana junto ao novo êxodo migratório, a relação dúbia com o país de investidura e as paisagens culturais transformadoras.
\end{abstract}

palavras-chave Brasileiros na Espanha. Políticas de representaçóes. Ideologias de pertencimento imputadas.

Durante a década de 1990, o incremento significativo de novas rotas internacionais e o

1. Este trabalho é o resultado de uma série de pesquisas de campo com grupos de brasileiros na cidade de Madri, realizadas em duas etapas: (a) dezembro a fevereiro de 2005, quando foram entrevistados trinta e dois brasileiros reconhecidos pela comunidade brasileira em Madri como os imigrantes mais antigos, anteriores a década de 1990; (b) dezembro a março de 2006, com mais quarenta entrevistas de brasileiros emigrados a partir da década de 1990, e especialmente de 1997 em diante, considerado um marco significativo no acréscimo de brasileiros à capital espanhola. Para as entrevistas com os brasileiros recém-chegados, constitui-se de vital importância a permanência diária no consulado brasileiro e na Casa do Brasil (Casa de Estudantes Brasileiros e Estrangeiros), como pontos de referência centrais para o conhecimento do perfil dos novos imigrantes. substancial acréscimo nas geografias migratórias (Sales, 1999) para os brasileiros que deixam o país, aprofundam um primeiro mito do Brasil como país exportador de imigrantes. Essas correntes que, de certa forma, inauguramse já na metade da década passada ${ }^{2}$, inserem o migrante brasileiro em uma paisagem condicionada pela busca da mobilidade social e pelo esforço da obtenção de uma mudança de fatores, tais como: emprego, renda, educação e acesso à saúde de qualidade.

Migram as primeiras correntes significativas e continuadas de brasileiros conduzidos pelas perpetuadas crises das décadas de 1980 e 1990 , sendo a vida na ilegalidade o marco constitutivo deste fluxo que deixa o país (Patarra, 1995), primeiramente com uma intençáo de retorno, depois, de modo paulatino, projetando um assentamento de médio e longo prazo.

O perfil do brasileiro que deixa o país durante esse período é substancialmente formado de jovens, trabalhadores, e, em muitos casos, estudantes com cursos universitários, que abandonam o país com a perspectiva de estabelecer-se

2. Segundo Sales (1999), mais de um milhão de brasileiros deixam o país a partir de 1985, motivados pelas sucessivas crises políticas e o desejo de mudança social impedida no Brasil. O perfil do migrante, naquele momento, era majoritariamente constituído de jovens que buscavam a solvência econômica a partir de alguns anos no exterior. Este projeto sofre uma mudança intensa com a possibilidade de obtençâo da dupla cidadania no ano de 1994 e com as novas procuras migratórias de assentamento a longo prazo no país de destino. 
no país de destino, procurando obter vistos de permanência definitivos e a possibilidade de livre transcurso entre o Brasil e o país escolhido.

A paisagem mutante dos primeiros anos de 2000 (Demartini; Truzzi, 2005), é de brasileiros já acostumados com as narrativas de impulsos migratórios internacionais e do Brasil como um país de abandono, de descrédito sistemático, alimentado pelas infinitas crises econômicas e as difíceis perspectivas de mudança social.

Embora os locais de destino preferencialmente almejados por esses novos brasileiros migrantes sejam bastante amplos e sujeitos à estruturação de redes sociais que angariam os primeiros projetos de imersáo nas sociedades abraçadas, o impulso migratório aos países ditos do primeiro mundo (Margolis, 1994; Sales, 1999) é prioritariamente mais importante. É esse fator que estabelece uma seqüência situacional de redes de divulgação - os casos de parentes e amigos bem-sucedidos - que muito influenciam o momento da partida.

Tanto pelo discurso das redes de informação pessoais (parentes, amigos, conhecidos) como pela mídia (programas de televisão, jornais e internet), as narrativas dos brasileiros que partiram e a divulgação das séries de experiências bem-sucedidas transformam-se em verdadeiros mecanismos de potencialização constante na decisão de deixar o lugar de origem. Nesse sentido, as sucessivas narrativas de mobilidade social e de solvência econômica privilegiadas ocupam um grau relevante nas representaçôes dos brasileiros que decidem partir.

Desta forma, ainda pouco explorada, a mídia contemporânea como meio de divulgação dos brasileiros no exterior, das distintas situaçôes econômicas dos países do "primeiro mundo" e os constantes noticiários sobre as sucessivas crises do país, exerce o papel de promover a multiplicidade de representaçóes coletivas dos brasileiros sobre a experiência da vida no exterior.
Imersos em um programa de certa maneira mundial de fluxos de partida para os países desenvolvidos, o caso dos brasileiros que escolhem o êxodo como modo de alterar os fatores sociais cristalizados ${ }^{3}$ demonstra a complexidade das correntes migratórias em uma paisagem universalizante em que a integração social (Medina, 2005) é o grande ponto condutivo e a questáo-chave no desenvolvimento de políticas adequadas e afirmativas para a alocação de novos grupos étnicos nas sociedades de acolhida.

Em se tratando da Espanha, onde primeiramente ocorreram as saídas migratórias à América Latina e depois as ondas migrantes internas foram ao longo de quase todo o século passado (Medina, 2005) a representação conhecida dos espanhóis, a súbita guinada de sociedade exportadora de migrantes para receptora em menos de quarenta anos trouxe e ainda conduz sérios problemas de integração social e reconhecimento de direitos específicos vinculados às minorias étnicas que assumem uma importância cada vez maior dentro da sociedade espanhola contemporânea.

No bojo dessas transformações apreendidas em um tempo bastante curto, aliadas ao incremento significativo e por vezes alarmante de pedidos de entrada e regularização da situação migratória, os imigrantes dos países latinoamericanos (Izquierdo, 1996) desempenham um papel determinante na imagem pré-política dos recém-chegados ao território hispânico, sendo a percepção social de uma suposta "invasão" latino-americana associada aos distintos grupos étnicos dos diversos países aos quais pertencem esses imigrantes.

3. Especificamente no caso brasileiro, onde a migração internacional é estabelecida primordialmente pelo imperativo do deslocamento social e mudança econômica significativa, antes que por motivos outros como os guerras étnicas, refugiados políticos, problemas de catástrofes naturais, etc. 
A representação social e a divulgação por parte da mídia das sucessivas tentativas de entrada no país de diferentes grupos étnicos, o esforço sistemático em detectar e estabelecer guetos culturais e a criação de tipologias étnicas como tentativa de compreender este fenômeno recente acabam alimentando a própria ideologia da invasão (Izquierdo, 1996). Servem, ainda, para a ativação de instâncias xenófobas (D’Ancona, 2004) conduzidas por séries de imagens tópicas contra os grupos migratórios.

Ainda que exista, como destaca Grinán (1997), uma posição marcadamente ambígua na vinculação social da imagem dos grupos migratórios e o estigma da invasão, bem como um posicionamento jurídico que de certa maneira assegura a positivação da condição forânea, o próprio conteúdo negativo da palavra "estrangeiro", como aponta a autora, acaba revelando uma associação fácil entre a representação negativa dos imigrantes e a ideologia da barbárie imaginada.

Nesse aspecto, mesmo que a maioria dos dados sobre os ritmos de entradas, segundo D'Ancona (2004), demonstre a inexistência real de um incremento relevante para que essa associação verdadeiramente se reproduza, o temor à invasão é um dado perceptível em várias estatísticas sobre a concentração de grupos de imigrantes no território espanhol.

Como mostra e analisa Izquierdo (1996), a percepção social sobre os diferentes grupos de imigrantes é bastante variada, mas a vinculação essencialmente negativa do temor da invasão, aliada a fatores como o aumento do desemprego, a competição laboral, a perda de privilégios de bem-estar social etc., contribui para forjar uma imagem geral de desconfiança e inquietude perante o fenômeno migratório.

Está claro mais uma vez que, em se tratando de uma sociedade como a espanhola, que passa por uma mudança radical na condição de país de abandono para país de retorno e de preferência de destino em táo curto espaço de tempo, há uma certa tendência em elaborar imagens preferencialmente negativas da condição do imigrante. A própria historicidade do país quando da construção da imagem étnica (Sepúlveda, 2004) justamente mediante a alteridade com o forâneo ${ }^{4} \mathrm{e}$ a perpetuação constante de uma certa idéia de identidade como signo de luta política contra a instabilidade das próprias representaçóes autodesmembrativas, que constantemente incidem sobre o complexo jogo de autonomias e direitos dos diferentes grupos que convivem no território espanhol, alimentam e desenvolvem uma focalização eminentemente negativa contra a vinda de outros grupos étnicos.

A idéia de um nacionalismo que pode sofrer transformações ameaçadoras a partir da ideologia da invasão também faz parte da maneira com que a sociedade de acolhimento (e repulsa) aprende como se constrói uma possibilidade de integração e quais são os imigrantes preferidos e como discriminá-los (ou confundi-los) com outros imigrantes.

A preferência pré-política pelos latino-americanos (Izquierdo, 1996) como perfil que mais se aproxima desta imagem étnica priorizada pela construção da hispanicidade (Sepúlveda, 2004) em contraposição, por exemplo, ao ideário relativo aos árabes e sua imagem de inintegráveis e problemáticos, ajuda a forjar uma percepção social, da qual se estabelecem certas dicotomias políticas construídas mediante um fluxo de particularidades bastante instáveis. Elas mesmas são permeadas pela memória de um nacional e determinadas por perspectivas

4. O papel desempenhado no imaginário popular e no próprio entendimento nacional a partir da retórica das imagens da reconquista e a alteridade profunda com o árabe, incitam em grande medida a um aprofundamento enfático na construção da diferença, fazendo com que o forâneo se torne ainda mais estranho e entendido como ameaça (Schur, 1971). 
diacrônicas em que as relaçôes sociais entre imigrantes e receptores sofrem uma série de processos bastante relevantes na adoção de imagens privilegiadas e pré-concebidas que ditam as regras das condiçôes de maior ou menor aceitação de distintos grupos étnicos.

A busca idealizante de uma suposta vinculação com as raízes formativas de uma etnicidade estabelecida como contraponto a uma série de imagens sobre outras populaçōes e o privilégio da hispanicidade como característica preferencial na divulgação de um imaginário nacional contemporâneo, efetuam uma série de cosmologias ideárias que, estruturadas por famílias de hierarquias étnicas, permitem vincular a possibilidade de convivência e o incremento de atitudes reativas contra alguns grupos de imigrantes.

Dessa maneira, a imagem do latino-americano como signo político adequado e culturalmente "mais próximo" a uma hispanidade desejável, ainda que veladamente, formaliza a possibilidade de integração na sociedade de acolhida. Nessa sociedade, o papel das instâncias étnicas é diluído e/ou ressaltado na dependência direta da concordância ou discordância destes símbolos relacionais estabelecidos e imediatamente potencializados no momento de fundamentar os projetos de convivência e na organização das diferentes tipologias de atitudes da sociedade espanhola ${ }^{5}$.

5. Segundo D'Ancona (2004), a variação discriminativa das atitudes frente aos grupos de imigrantes em território espanhol, é singularmente marcada por uma atitude genérica de tolerância moderada. Ainda que a pluralidade de capacidades reativas seja feita sob um leque amplamente variado de possibilidades de aceitação e rechaço, dependendo de uma série bastante grande de fatores condicionantes mais ou menos explorados, a sociedade espanhola assume uma condição passivamente tolerante frente ao tema da imigração, ainda que as encostas revelem também, segundo esta autora, uma preocupante e crescente ideologia do estigma da invasão.
Mas a aceitação dos imigrantes latino-americanos náo é irrestrita e sim vinculada à uma falsa impressão que se constrói sob o paradigma da convivência coletiva determinada por uma certa busca de uma concordância étnica que desenvolva a "latinidade" como uma alteridade "suave" ante a hegemonia hispânica.

$\mathrm{O}$ estigma da incapacidade de integração social associado aos árabes, segundo Izquierdo (1996), em comparação aos latino-americanos, gera realidades complexas elaboradas com base nas historicidades locais que estruturam percepçóes relativas de um ou outro grupo étnico.

No entanto, como aponta Medina (2005), a imigração ao território espanhol acontece preferencialmente às grandes urbes, sendo Madri e Barcelona os pólos principais de atração desses novos migrantes, onde a tipologia de atitudes e a tolerância moderada espanhola sofrem influências bastante significativas ${ }^{6}$.

A proximidade permite a acentuaçáo xenofóbica e a ativação das posições discriminatórias. Segundo dados do Centro de Investigaciones Sociológicas (CIS) publicados em janeiro de 2006 (CIS, 2006), em uma série de pesquisas sobre os três primeiros problemas relativos à Espanha atual, 29,4\% dos entrevistados situaram a imigração em segundo lugar, atrás apenas do temor ao desemprego e à frente de problemas como o terrorismo e os nacionalismos das comunidades autônomas. Constata-se por meio de dados que a divulgada tendência a uma certa

6. Se o aumento da tendência em pensar que os imigrantes são muitos de $31 \%$ em 2000 para 53\% em 2004, segundo dados expostos pelo autor (Medina, 2005), incorre em uma percepçáo cada vez mais desordenada do ritmo de entradas, estes dados apontam que são nas grandes metrópoles que a ideologia da invasão, associada ao temor da competição laboral, aumento da criminalidade e perda de benefícios de bem-estar social, efetivamente incrementa-se. Neste âmbito, o papel desempenhado pela mídia na divulgaçáo diária de casos relacionados aos grupos migrantes é um fator importante a ser analisado. 
"tolerância leve" (CIS, 2006, p. 25) por parte dos espanhóis em relação aos grupos imigrantes, com acessão dos árabes e o imaginário da reconquista, esteja cada vez mais próxima a uma cartografia de descontrole e incremento espetacular dos imigrantes em território espanhol.

Associados a isso, a freqüente inabilidade em administrar consensualmente políticas de coexistência pacífica e a falta de tradição de diretrizes de integração, ao lado do despreparo, segundo Izquierdo (1996) e Medina (2005), por parte dos governantes em adotar medidas de integração multiculturais, e, sobretudo, com o privilégio do pertencimento da hispanicidade colocada, impulsionam ainda mais a psicose da invasão.

Ao estabelecer-se uma imagem tópica geralmente negativa da alteridade, vistas nestas condiçôes como o aprofundamento da "estrangeirização" do estranho, ressaltam-se dicotomias étnicas alimentadas por posturas cada vez mais racistas.

No caso dos latino-americanos, essa tradicional tendência pré-política à aceitação sofre constantemente uma série de vinculações contraditórias por meio das imagens midiáticas e da exploraçấo de temas relativos à marginalidade em certos jornais, nos quais a visão tópica dos "latinos" como "dóceis", "submissos", "integráveis", alimenta-se também na visão de "delinqüentes", "perigosos", “instáveis" e "indolentes".

O reforço, nesse aspecto, de uma espécie de nova estereotipia contra o latino é também uma busca pelo afastamento de uma identidade

7. Como apontado por Feres (2005), a construção do americanismo nos Estados Unidos foi estabelecido em parte como contraposição aos "latinos", vistos classicamente como "incivilizados", "incultos", "católicos" e "preguiçosos". Neste sentido, contrariamente ao observado pelo espanhol, a "identidade latina" foi a alteridade maior e o contraponto à confecção do americanismo prevalecente, onde outras alteridades tiveram o privilégio pré-político de reconhecimento participativo, como ingleses e irlandeses. anterior reconhecida como próxima a certas características que se pretendem desaparecidas ou "superadas".

A entrada da Espanha na comunidade européia significa também um novo signo político e um marco geracional no qual a "hispanidade" é alimentada tanto pela negociação com novos signos e influências modernas, como pela necessidade de expurgar certas características que anteriormente demarcavam o espelhamento étnico. É também neste sentido que o latinoamericano perde a preferência pré-política e sofre amplamente um processo contemporâneo de afastamento pelo medo da invasáo.

O grau de tolerância nas sociedades receptoras de imigrantes, como ressaltam González e Requena (2005), depende da própria percepção social do imigrante como um componente necessário ao contínuo crescimento do país ou como uma ameaça (Saborit, 2006), que endossa o temor à destruiçáo de privilégios conseguidos. No caso da Espanha moderna, essa mudança súbita de país de partida para de entrada, juntamente com a preferência cada vez mais acentuada pelo imigrante temporal, a histórica aversão à hibridação excessiva e a sempre frágil universalidade de um imaginário nacional no âmbito das polaridades internas, promovem um temor contínuo que se estende ao latino-americano.

A associação fácil entre delinqüência e imigração latina, constantemente permeia a vinculação de maior tolerância com os latinos e, embora essa sociedade não os focalize como "árabes", acaba incrementando novas opinióes negativas sobre os projetos comunitários de convivência. A imagem tradicional que pontuava o "latino-americano" como "mais próximo" ao latino ibérico, de certa forma, encontra resistências pelo próprio reforço da hispanicidade frágil, uma vez que a instabilidade secular da nacionalidade espanhola, em se tratando de miscigenação de projetos de convivência, aparece contemporaneamente 
como um dinâmico restabelecer de elementos culturais entendidos como mais evidentes.

Não obstante, é preciso lembrar que essa mudança, ora de apoio ou tolerância velada à imigração latina, ora de atitudes de desconfiança e temor dada à estrangeirizaçáo excessiva da naçáo, é localizada e necessariamente dependente das circulaçôes de informações (Castles, 2000) de uma sociedade ainda pouco familiarizada com a chegada massiva de imigrantes.

Evidentemente, a própria noção da multiplicidade dos grupos migratórios que chegam às terras espanholas é reconhecida. No entanto, o aumento, muitas vezes percebido como excessivo da imigração, alimentado ainda pela alta clandestinidade e pela tendência à banalização do fenômeno por parte dos meios de comunicação (Nash, 2005), vincula uma série de discursos que são perigosamente homogenizadores e que fazem do imigrante um estrangeiro único, estabelecido por repertórios de estigmatização que tendem a criar certa generalização sobre a experiência da alteridade migratória.

No plano midiático, a condução de informações sobre a chegada de grupos migrantes em terras espanholas é estabelecida pela divulgação do fenômeno dos "ilegais" como notícia (Nash, 2005), juntamente aos relatos de casos de marginalidade e delinqüência callejera. A uniformização retórica sobre as informaçóes recorrentes dos imigrantes que chegam às cidades espanholas e a exposiçáo cotidiana nas redes de informação que privilegiam as notícias sobre clandestinidade e marginalidade, contribuindo para aumentar ainda mais a percepção social de descontrole e falta de regulação sobre a chegada de imigrantes, trata de tipificar negativamente a multiplicidade de imigrantes que se destinam ao país ${ }^{8}$.

8. É interessante observar a exploração diária do fenômeno migratório na mídia, especialmente o problema das vindas das famosas pateras que chegam às costas canárias, e a percepçáo generalizada de profundo descontrole e falta de entendimento das autoridades
A politização favorável de uma europeização que se valoriza amplamente, em contraposição a outras formas de aproximação cultural anteriormente existentes na construção de um imaginário coletivo espanhol, acaba produzindo constantemente novos elementos de discursos que tipificam alteridades culturais, antes entendidas como aliadas, em novas representaçóes de ameaças, ao mesmo tempo em que a hibridação européia é ressaltada e o ibericismo é refeito por uma política de alternância?.

Especialmente os brasileiros, como "latinoamericanos" moderados, longe de serem associados facilmente à produção moderna da "barbárie imaginada" (Hudron, 1993), mas também suficientemente próximos da latinidade para serem imersos na estrangeirização discursiva com a xenofobia condescendente amparando a percepçáo social influenciada pela agenda midiática, o fator ibérico é um componente determinante em que a produção de um imaginário social acaba conduzindo a caracterização de conformidades culturais que potencializam uma série de registros étnicos.

O fenômeno dos brasileiros na Espanha assume múltiplas especificidades, em particular quanto à própria percepção social de uma invisibilidade constitutiva ${ }^{10}$. $\mathrm{O}$ freqüente aumento

frente ao âmbito das novas migraçôes internacionais. A transmissáo contínua de relatos sobre ilegalidade e estrangeirismo fomenta de modo significativo a apreensão popular sobre a migração, como demonstra mais uma vez Nash (2005).

9. Enquanto signo econômico, o ibericismo é entendido de certa maneira e singularmente aproveitado para o estabelecimento de laços e acordos comerciais entre os países latino-americanos e a Espanha. Não obstante, a alteridade entre o "ibérico" e o "hispânico" é também um marco conceptual e uma memória política estabelecida pela alternância e pela prevalência de certos horizontes culturais vistos como possibilidades e impedimentos na hora de conduzir políticas migratórias.

10. Como demonstra Ripoll (2006), estatisticamente os brasileiros na Espanha ainda são poucos em comparação a outros grupos de migrantes latino-americanos. 
no ritmo de entrada dos brasileiros desde a virada do século passado e a projeção constante na mídia dos outros grupos latino-americanos vêm associando os brasileiros em um programa único de leituras das correntes migratórias latinas que colocam a alteridade ibérica como marco constante nas estratégias de etnificação.

Os brasileiros também acabam sendo inseridos paulatinamente no jogo de leituras das alteridades culturais, ainda que a conduçáo de estatutos de diferença recebam tratamento diversos entre os novos espaços de definiçóes e redefiniçóes constantes por parte da sociedade espanhola. A relação complexa entre as políticas de identidades e a percepção mesma por parte dos espanhóis da variedade de perfis culturais entre os latino-americanos certamente se refletem no caso dos brasileiros, assim como no dos argentinos e mexicanos. O "ibericismo" igualmente atua como estratificador funcional no momento de se desenhar tipologias coletivas que vinculam uniformidades segmentárias e ajudam a imputar blocos de estereotipias generalizantes.

Para os brasileiros, a própria questão da "latinidade" é fundamentalmente um discurso bastante manipulado no ato da construçáo de uma série de alianças e vantagens. A exposição na mídia do incremento dos números em contínua elevação (Ripoll, 2006) de grupos de brasileiros recém-chegados às terras espanholas, causa um novo desconforto e o receio da marginalização e da estereotipia étnica.

Como são, historicamente, um grupo que na foraneidade tende (Sales, 1999) a acentuar a hibridação e a adaptabilidade como recursos contra a guetificação e com um repertório de saída das cosmologias étnicas imputadas,

Mas, segundo a autora, os brasileiros foram o terceiro maior coletivo em crescimento a partir de 2004, somente atrás dos bolivianos e dos romanos. A invisibilidade dos brasileiros ainda acontece, mas o incremento estatístico sem dúvida pode transformar rapidamente a percepção social apagada. os brasileiros no exterior transitam como um coletivo imerso na dispersão e invisibilidade. No caso dos brasileiros na Espanha, estatisticamente um grupo ainda pouco expressivo mas em forte expansão, a mestiçagem como recurso edênico é um fenômeno amplamente utilizado tanto na hora de "desaparecer" dos censos migratórios como no momento de fugir ou internalizar a exotificaçáo tropicalista ${ }^{11}$.

Não obstante, sob a brasilidade "clássica", as novas ondas migratórias internacionais durante a década de 1990 colocam uma variedade de perfis de brasileiros migrantes, que deixam o país geralmente pelos sucessivos descréditos quanto às possibilidades de transição social, acompanhando de perto a oscilação das incertezas políticas e a produçáo de novas angústias pela freqüente instabilidade econômica. Como coletivos de abandono, brasileiros cada vez mais jovens e com escolaridade diversa migram aos países de primeiro mundo, passando também a mudar conseqüentemente os projetos de solvência econômica para implementar os projetos de permanência prolongada, sem o imediatismo do retorno, procurando levar seus familiares e reproduzir redes de sociabilidades preestabelecidas.

Mas os novos brasileiros na Espanha não procuram formalizar grupos tanto para fugir $\mathrm{da}$ exotificação tropicalista e dos projetos de arcaicização tópica ${ }^{12}$ quanto pelas vantagens da adaptabilidade cultural. Neste aspecto, a mestiçagem

11. A fantasia tropical e o imaginário coletivo associado aos brasileiros, juntamente com alguns segmentos - casas com temáticas de festas brasileiras, restaurantes tropicais, espetáculos musicais e artísticos, escolas de capoeira e cursos de idiomas -, ajudaram a forjar uma política de identidade "brazuca" que, no caso da Espanha, foi um produto economicamente rentável dos primeiros brasileiros migrados, fundamentalmente constituído por artistas, jogadores de futebol, empresários de casas de restaurante e bares com a temática tropicalista.

12. No limite, a associação tradicional entre brasilidade e "povo alegre", "mulheres promíscuas", "jogadores de futebol", "bons músicos" etc. 
interior, nacional e constitutiva dos brasileiros é reproduzida e reforçada em terras hispânicas como contraponto imediatamente positivo da fuga das caracterizaçôes genéricas ocasionadas pela fantasia tropicalista e pelo incremento numérico nos censos demográficos. $\mathrm{A}$ não-busca pela formalização étnica e a série de vantagens abraçadas pelo recurso da inexistência de estatística expressiva argumentam com a instituição da adaptabilidade, demonstrando que a etnificação acontece justamente pela potencialização da invisibilidade-amálgama, mediante um assimilacionismo edênico que serve como artifício consciente para driblar aparências estigmatizadoras ${ }^{13}$.

Quando a invisibilidade reforçada produz uma conveniência simbólica além da caracterização, um ideário baseado no momentâneo desaparecimento é recebido como discurso e estratégia de resistência que ilude os censos demográficos e também causa uma percepção social do reduzido número de imigrantes. A imigração silenciosa e a tendência moderada pela dispersão e adaptabilidade produzem uma série de constâncias na qual a estratégia brasileira para com o ibericismo é justamente a de ora se aproximar ora se distanciar de uma latinidade que se desenha preferencialmente no momento de estabelecer uma série de dicotomias e hierarquias de privilégios pré-políticos com a hispanicidade.

Entretanto, a exposição cada vez mais elevada nos censos populacionais gera o perigo do incremento perceptivo, ao mesmo tempo em que abre portas para o fenômeno estigmatizador, colocando os brasileiros em uma condição muito mais evidente e visível para a população espanhola.

13. Também é preciso ver que os brasileiros tendem a migrar para grandes urbes no cenário espanhol, onde essa adaptabilidade certamente pode acontecer como maior ocasiáo e o "desaparecimento" estatístico se produz mais facilmente. Note-se, ainda, a quase inexistência de associaçóes culturais e comunitárias entre os brasileiros em Madri e Barcelona, bem como a não aglomeração, ao contrário de outros grupos latino-americanos (Izquierdo, 1996) em bairros e localidades típicas.
Dentro do alarde midiático que repercute a imigração internacional na Espanha contemporânea, além da sensação genérica de descontrole e da falta de capacidade para lidar com um fenômeno recente (Medina, 2005), a ideologia do temor da invasão reproduz-se em coletivos de incremento como os brasileiros, permitindo uma aproximação tópica e simplista com outros grupos étnicos latino-americanos. No caso do perfil dos novos grupos de migrantes brasileiros, especialmente os migrados a partir da segunda metade da década de 1990, que se constituem de jovens entre 25 e 34 anos em idade laboral (Ripoll, 2006), essa nova transformação social, associada à agenda contemporânea da barbarização do forâneo, acaba administrando generalidades e colocando os brasileiros junto a outras polaridades (latinoamericano).

Nesse sentido, o terror da invasão latino-americana é estendido também aos jovens brasileiros em idade laboral, compondo uma uniformização dos grupos étnicos e ressaltando a dicotomia cultural como discurso político que produz uma evidência de alteridade determinante. A estrangeirizaçâo da norma estética e a diabolização do outro como signo da ideologia da invasão não permitem aos brasileiros refugiar-se nas especificidades do tropicalismo, quando historicamente apareciam como coletivo "exótico", "agradável" e "distante". A nova produçáo do estigma do latino-americanismo delitivo atua como uma capa retórica que formaliza as séries de visóes etnocêntricas e ao mesmo tempo impede as nuanças do dado cultural.

No caso dos brasileiros, em que a etnicidade aparece justamente na procura pela adaptabilidade híbrida a toda prova e a mestiçagem mostrase como estratégia importante na hora de passar invisivelmente pelos censos demográficos e pela percepção uniforme da populaçáo, a homogeneização de realidades díspares e o desaparecimento das amplitudes tênues acabam instituindo os coletivos em blocos genéricos perigosamente 
associados às imagens contemporâneas de incremento, descontrole e perigo da imigração.

No limite, a imagem dos brasileiros ainda transita pluralmente entre um tropicalismo estrangeiro, assentado sob uma visão ligeiramente positiva e tolerante da foraneidade "exótica" pela qual os brasileiros aparecem como "artistas", "bons músicos" e "povo alegre", sobretudo em pequenos números que não chegam a incomodar, e o contraponto de um latino-americanismo crescente e ameaçador.

Entre esse tropicalismo de sobrevivência e a uniformização latino-americana, aliados à nova agenda política e ao fenômeno da espetacularizaçáo da imagem da invasão, os brasileiros seguem migrando em um número crescente, concentrando-se nas grandes urbes espanholas e praticamente aparecendo em todos os setores de emprego migratórios, desde serviços de construção civil. Vítimas e protagonistas de uma nova identidade em que se desenham cartografias étnicas de acordo com aproximação e distanciamento da imagem do imigrante, a tradicional não formalização em guetos culturais e a retórica da adaptabilidade a qualquer custo, gradualmente, formalizam novas perspectivas e tendências culturais, em que o brasileiro é inserido em uma alteridade que tende à homogeneização de vozes culturais discrepantes sob efeito de uma leitura mutilada do dado semântico.

Mais expostos, menos capazes de criar tantos artifícios para conseguir esconder-se entre o abandono e a transposição numérica, a brasilidade associa-se ao coletivo latino-americano, entre redes de conflitos alimentados negativamente pelas outras pluralidades em que os itinerários culturais são feitos a partir da linguagem tópica da ameaça e um disseminado discurso da transmissão de imaginários coletivos em polaridades construídas na estrangeirização do outro.

As novas paisagens diaspóricas assumem contextos marcados pela anonimidade e a guetificação impostas. O desaparecimento é uma tentativa e um recurso comunicativo da invisibilidade de resistência utilizada pelos brasileiros como maneira de escapar da norma especulatória, tornando-se um recurso mínimo diante da ideologia da barbarização. Esta sim, alimenta-se fartamente da conflitualização do outro e da incomensurabilidade dos novos interesses migratórios: projetos de assentamento de longo prazo, tolerância ativa.

Antes associados à musicalidade, ao tropicalismo exótico e ao futebol, ao carnaval e às mulheres exuberantes, os brasileiros na Espanha passam a entrar também, como outros grupos latino-americanos, nas pautas dos discursos midiáticos, mais expostos e visíveis dentro da operaçáo política de estabelecimento de dicotomias étnicas. Sem fugir de todo ao estigma da brasilidade, deixam de ser vistos como os excelentes músicos da bossa nova de outrora e cada vez mais como sin papeles ${ }^{14}$, "sem papéis", sem alteridade positiva e com a ameaça constante da retórica reguladora contra os que, sem documentos, dentro da ilegalidade, absorvem a representação social dos discursos do medo e do sentimento xenofóbico diante da imigração contemporânea na sociedade hispânica.

\section{We were "Bossa Nova". Today we are sin pa- peles: transnationalism, belonging and identity in Brazilian migrants representations in Spain}

abstract This work is a reflection on the aftermodern condition of the new Brazilian migrantes to the Spanish cities, breaking of a case study the Brazilians in the capital of Spain. The quarrel on transnacionalism and marginality, the processes and the

14. O uso de dicotomias forâneas para se referir à imigraçấo, aproximando a abordagem do tema por termos cunhados nos Estados Unidos (espaldas mojadas) e na França (sin papeles), tem sido demonstrado (Nash, 2005) ao salientar a dificuldade de problematizar como a imigração realmente afeta o cotidiano espanhol. 
directions of belonging, the new politics and ideologies of representations and the migratory flows are boarded from the analysis of the proper process of Brazilian immigration in Madrid. The concern biggest, therefore, is to argue an ethnicity flowed since a central axle - cultural memory and transnational identity - being observed the representations of the Brazilians in Spain in its new migratory flows. The article still intends to trace a reflection on the question contemporary of the establishment of series of differences and landmarks, the multiculturalism as a modern idea in the Europe and the influences for the emigrated ones from Brazil. The question of the just-discovery Latin American identity next to the new migratory exodus, the relation with the investiture country and the cultural homesicknesses.

keywords Transnational Brazilians in Spain. Identities. Politics of representations.

\section{Referências bibliográficas}

CASTLES, Stephen. Migración internacional a comienzos del siglo XXI: tendencias y problemas mundiales. In: Revista Internacional de Ciencias Sociales, n. 165, p. 17-32, septiembre 2000. Disponível em: http://portal.unesco.org/shs/en/files/3795/107537 14551 fulltextspa165.pdf. Acesso em: 19/02/2005.

CIS (Centro de Investigaciones Sociológicas). Informe Diagnóstico Imigratório Anual. Madrid: CIS, 2006. 192p.

D’ANCONA, Maria Ángeles Cea. La activación de la xenofobia en España: ¿Qué miden las encuestas?. Madrid: CIS, 2004. 304p. (Colección Monografias).

DEMARTINI, Zeila de Brito Fabri; TRUZZI, Oswaldo Mário Serra (Orgs.). Estudos migratórios: perspectivas metodológicas. São Carlos: Edusfcar, 2005. 221p.
FERES, João. A história do conceito de "Latin America" nos Estados Unidos. Bauru: Edusc, 2005. 317p.

GONZÁLEZ, Juan Jesús; REQUENA, Miguel (org). Tres décadas de cambio social en España. Madrid: Alianza, 2005. 352 p.

GRIŃÁN, Patricia Barbadillo. Extranjería, racismo y xenofobia en la España contemporánea: La evolución de los setenta a los noventa. Madrid: CIS, 1997. 207p. (Colección Monografias).

HUDRON, Laennec. El barbaro imaginário. Mexico: Fondo de Cultura Econômica, 1993. 224p.

IZQUIERDO, Antonio. La inmigración inesperada: la población extranjera en España (1991-1995). Madrid: Editorial Trotta, 1996. 288p.

MARGOLIS, Maxine. Little Brazil: imigrantes brasileiros em Nova York. Campinas: Papirus, 1994. 452p.

MEDINA, Luis Garrido. La inmigración en Espana. In: GONZÁLEZ, Juan Jesús; REQUENA, Miguel (eds). Tres décadas de cambio social en España. Madrid: Alianza Editorial, 2005. p. 127-164.

NASH, Mary. Inmigrantes en nuestro espejo: inmigración y discurso periodístico en la prensa española. Barcelona: Icaria Antrazyt, 2005. 165p. (Colección Icaria Antrazyt 231).

PATARRA, Neide. Emigração e imigração internacionais no Brasil contemporâneo. São Paulo: FNUARP, 1995. 276 p.

RIPOLL, Érika Masanet. O Brasil e a Espanha na dinâmica das migraçóes internacionais: um breve panorama da situação dos emigrantes brasileiros na Espanha. 2006. XV Encontro Nacional de Estudos Populacionais, ABEP, Caxambu. Disponível em: http://www.abep.nepo. unicamp.br/encontro2006/docspdf/ABEP2006_499. pdf. Acesso em: 20/12/2006.

SABORIT, Pere. Vidas adosadas: el miedo a los semejantes en la sociedad contemporánea. Barcelona: Anagrama, 2006. 184p. (Colección Argumentos, 346).

SALES, Teresa. Brasileiros longe de casa. São Paulo: Cortez, 1999. 232p.

SCHUR, Edwin. Labeling deviant behavior: its sociological implications. New York: Harper \& Row, 1971. 177p.

SEPÚLVEDA, Isidro. El sueño de la Madre Pátria. Madrid: Marcial Pons, 2004. 530p.

\section{autor Rafael Tassi Teixeira}

Professor do Departamento de Antropologia/Universidade Tuiuti do Paraná

Doutor em Filosofia/Universidad Complutense de Madrid

Doutor em Sociologia/UnB

Recebido em 26/03/2007

Aceito para publicação em 04/10/2007 